\title{
AS ORIGENS EXISTENCIALISTAS DE HEIDEGGER: A INFLUÊNCIA DA TEORIA KIERKEGAARDIANA DA COMUNICAÇÃO INDIRETA *
}

The existentialist roots of Heidegger: the influence of Kierkegaard's theory of indirect

communication

Juliana Missaggia **

Resumo:: Nesse artigo analiso o modo como a teoria da comunicação indireta, desenvolvida por Kierkegaard, influenciou o pensamento de Martin Heidegger. Primeiramente, faço uma breve exposição da relação da filosofia heideggeriana com a tradição filosófica, o existencialismo e Kierkegaard. A seguir, exponho quais são as principais características e o modo de aplicação da teoria da comunicação indireta, tal como desenvolvida pelo filósofo dinamarquês. Por fim, mostro como essa ideia influenciou Heidegger no que diz respeito principalmente a questões metodológicas.

Palavras-chave: Heidegger, Kierkegaard, Existencialismo, comunicação indireta.

\begin{abstract}
In this article I analyze how the indirect communication theory, developed by Kierkegaard, influenced Martin Heidegger's thought. Firstly, I make a brief exposition of the relation among Heideggerian philosophy, philosophical tradition, existentialism and Kierkegaard. Next, I exhibit what are the main features and the way of application of the theory of indirect communication, as developed by the Danish philosopher. Lastly, I show how this idea influenced Heidegger mainly with regard to methodological questions.
\end{abstract}

Keywords: Heidegger, Kierkegaard, Existentialism, indirect communication.

\footnotetext{
* Agradeço à revista Intuitio e ao Editor-Gerente José Leonardo Ruivo pelo convite de publicar nessa edição como autora convidada. Meu agradecimento também a Felipe Dal Prá pela leitura e generosas sugestões.

** Doutora em Filosofia pela PUC-RS, professora de Filosofia da Universidade Católica de Pernambuco.
}

\begin{tabular}{|c|c|l|l|c|c|}
\hline intuitio & $\begin{array}{c}\text { ISSN } \\
1983-4012\end{array}$ & Porto Alegre & Vol.8 $-\mathrm{N}^{\mathrm{o} .2}$ & $\begin{array}{c}\text { Dezembro } \\
2015\end{array}$ & p.04-14 \\
\hline
\end{tabular}


Juliana Missaggia

As origens existencialistas de Heidegger: a influência da teoria kierkegaardiana da comunicação indireta

\section{Heidegger, Kierkegaard e o existencialismo}

Heidegger é reconhecido como um ávido e incansável leitor da história da filosofia. São famosas, assim como polêmicas, as suas interpretações dos mais importantes pensadores. Se considerarmos que o próprio Heidegger deixava claro que partia de uma destruição da história da filosofia e sempre reafirmava a importância do confronto com a tradição, não deve então soar surpreendente seu vasto campo de interesse, assim como a inovação que podemos perceber em suas interpretações. Sua Destruktion não pode, porém, ser confundida com uma devastação do pensamento filosófico, pois seu objetivo é realizar uma desconstrução daquilo que é explicitamente dito pelos textos, de maneira que seja possível acessar as bases ontológicas ocultas na investigação ${ }^{1}$.

Ao se apropriar da tradição filosófica, Heidegger pretendia ir além da mera interpretação de textos e da análise crítica: o objetivo fundamental era encontrar as experiências originárias que possibilitaram as intuições mais fundamentais sobre o sentido do ser e que motivaram as questões filosóficas até hoje pertinentes. Ao pretender revelar aquilo que permanecia obscuro e subentendido, haveria a possibilidade de encontrar uma fonte de inspiração para um pensamento ao mesmo tempo basilar e original. Embora a abordagem fosse inteiramente nova, os problemas eram, em certo sentido, os mesmos: o problema do sentido do ser, por exemplo, podia reaparecer sob um novo ponto de vista - como crítica e também como retomada da tradição.

Como se sabe hoje, essa apropriação original da filosofia foi fundamental para o desenvolvimento de Ser e Tempo ${ }^{2}$, como atestam os diversos cursos que Heidegger ministrou ao longo dos anos 20, entre os quais se incluem estudos sobre a obra de Kierkegaard ${ }^{3}$. Como demonstra o excelente trabalho de Kisiel $^{4}$ sobre o desenvolvimento da obra magna heideggeriana, as investigações do filósofo alemão sobre o pensamento de Kierkegaard começaram juntamente com suas pesquisas sobre a teologia mística, mas muitas das ideias que depois foram identificadas como propriamente "existencialistas" no pensamento kierkegaardiano foram fundamentais para diversos conceitos que são desenvolvidos em Ser e Tempo.

Como analisarei em mais detalhes adiante, uma das questões centrais na primeira fase do pensamento heideggeriano que foi fortemente influenciada por Kierkegaard diz respeito ao próprio o método e sua formulação a partir das indicações formais (formale Anzeige). O contexto da formação da nova metodologia surge na busca por uma filosofia que permitisse o acesso à vida fáctica e concreta, no

\footnotetext{
1 Sobre a Destruktion heideggeriana, ver Inwood (INWOOD, Michael. Dicionário Heidegger, 1999, p. 159-61).

${ }^{2}$ HEIDEGGER, Martin (1927). Sein und Zeit.

${ }^{3}$ Como, por exemplo: HEIDEGGER, Martin. (GA 63). Ontologie (Hermeneutik der Faktizität) (Sommersemester 1923), HEIDEGGER, Martin. (GA 60). Phänomenologie des Religiösen Lebens (Wintersemester 1920/21) e HEIDEGGER, Martin. (GA 17). Einführung in die phänomenologische Forschung (Wintersemester 1923/24).

${ }^{4}$ KISIEL, Theodore. The Genesis of Heidegger's Being and Time.
}

\begin{tabular}{|c|c|c|c|c|c|}
\hline intuitio & $\begin{array}{c}\text { ISSN } \\
1983-4012\end{array}$ & Porto Alegre & Vol.8 $-\mathrm{N}^{\mathrm{o}} .2$ & $\begin{array}{c}\text { Dezembro } \\
2015\end{array}$ & p.04-14 \\
\hline
\end{tabular}


As origens existencialistas de Heidegger: a influência da teoria kierkegaardiana da comunicação indireta

seu componente histórico, prático e inserido na chamada hermenêutica da facticidade ${ }^{5}$. O modo como a filosofia da tradição abordava as questões parecia não levar em conta a realidade dada, com todas suas contingências e cotidianidades. $O$ tratamento conferido ao conhecimento tendia a focar no objeto e a caracterizá-lo de um modo totalmente teórico. O próprio sujeito do conhecimento era descrito em filosofia geralmente como um sujeito "descarnado" e separado do mundo dos objetos - o que gerava uma dualidade que dificilmente permitiria reconciliação. $O$ caráter histórico e temporal presente na compreensão era muitas vezes simplesmente ignorado, ou então não suficientemente desenvolvido, a ponto de os filósofos não perceberem a base concreta na qual repousava a teoria por eles formulada. As indicações formais surgiam justamente como uma alternativa para essas dificuldades ${ }^{6}$.

Nesse sentido, a apropriação de Heidegger da filosofia de Kierkegaard é também interessante como um meio para indicar e compreender melhor o enorme potencial e originalidade da obra kierkegaardiana, a despeito de que por vezes o pensador dinamarquês sequer seja considerado propriamente um filósofo. Do mesmo modo, essa análise é interessante no sentido de lançar luz sobre o modo como a história da filosofia influenciou Heidegger, e como suas contribuições, mesmo as mais inovadoras, estavam assentadas no seu constante diálogo com a tradição - em coerência, aliás, com o princípio hermenêutico defendido por ele de que toda filosofia nasce do confronto com os pensadores que nos antecederam e em consonância com nosso contexto histórico.

Outro aspecto interessante da relação entre Heidegger e Kierkegaard é que ambos são comumente classificados por historiadores da filosofia como "existencialistas": Kierkegaard, embora não usasse esse termo, é muitas vezes denominado de "o primeiro existencialista"; ; Heidegger, por outro lado, negava qualquer relação com a corrente filosófica representada por Sartre e Simone de Beauvoir, mas nem por isso escapou de ser, também ele, chamado de "o pai do existencialismo" ". O que está por trás dessas classificações é, em primeiro lugar, o entendimento - do qual compartilho - de que a corrente existencialista não pode ser definida e situada apenas pelo seu desenvolvimento na França a partir dos $\operatorname{anos} 40$.

5 Conforme esclarece Gadamer (GADAMER, Hans-Georg. Los caminos de Heidegger,2002, p. 282): "Pois facticidade quer dizer o fato em seu ser-fato, ou seja, justamente aquilo do qual não se pode voltar atrás. Também em Dilthey (...) já se encontra a caracterização da vida como fato do qual não se pode voltar atrás. E sem dúvida é parecido em Bergson, Nietzsche e Natorp. (...) Portanto, hermenêutica da facticidade é um genitivus subjectivus. A facticidade se põe, ela mesma, na interpretação. A facticidade que se interpreta a si mesma não junta em si mesma conceitos que a interpretariam, mas sim é um modo do falar conceitual que quer agarrar sua origem e com ela seu próprio alimento vital, quando se transforma à forma de uma proposição teórica".

6 Para uma visão mais geral das indicações formais, ver STREETER, Ryan. Heidegger's Formal Indication: a Question of Method in Being and Time, 1997.

${ }^{7}$ Ver, sobre esse debate acerca da classificação de sua filosofia: FRIEDMAN, R. Z. Kierkegaard: First Existentialist or Last Kantian?, 1982.

${ }^{8}$ Kenny, A. A New History of Western Philosophy, 2010, p. 820.

\begin{tabular}{|c|c|l|l|c|c|}
\hline intuitio & $\begin{array}{c}\text { ISSN } \\
1983-4012\end{array}$ & Porto Alegre & Vol.8 $-\mathrm{N}^{\mathrm{o} .2}$ & $\begin{array}{c}\text { Dezembro } \\
2015\end{array}$ & p.04-14 \\
\hline
\end{tabular}


As origens existencialistas de Heidegger: a influência da teoria kierkegaardiana da comunicação indireta

No entanto, certamente não é tarefa fácil encontrar uma definição adequada para o existencialismo. Uma breve análise de enciclopédias e dicionários de filosofia é suficiente para constatar a fragilidade dos conceitos apresentados, os quais não parecem dar conta do tema. O mais comum é se apresentar uma definição que acaba, pelos próprios termos utilizados, restringindo o existencialismo ao pensamento de Sartre ou outro existencialista em particular, ou então conceituar tal corrente filosófica de modo tão abrangente que, no limite, ela sequer chega a se diferenciar de outras filosofias.

Um exemplo desse último caso é definir o existencialismo simplesmente como uma área da filosofia que tem como uma das questões centrais o "interesse pela humanidade enquanto tal e suas relações com o mundo". . A questão que surge diante disso é se não há diversos filósofos que também trataram da questão da humanidade e sua relação com o mundo, mas que, ainda assim, não eram existencialistas. A não ser que à especificação "enquanto tal" se atribuísse um preciso conteúdo conceitual, que o autor não fornece e a nosso juízo tampouco poderia fornecer, uma vez que a delimitação mesma da região do "humano" (portanto do "humano enquanto tal") varia conforme as filosofias e, assim, só adquire sentido aferidor desde dentro de cada uma delas, não podendo portanto servir de conceito mediador. Podemos mesmo concluir que essa definição é tão geral que nesse caso poucos pensadores não seriam classificados como representantes do existencialismo.

Esse não é um problema apenas secundário, pois, especialmente se tratando de filosofia, a dificuldade de definir costuma acompanhar uma dificuldade na própria compreensão do tema. Uma maneira de contornar tal obstáculo é, com costumam fazer as enciclopédias e dicionários, apontar não somente uma definição ampla e abrangente como a que mencionamos, mas também listar, adicionalmente, alguns temas importantes e que seriam questões comuns a diversos filósofos classificados como existencialistas, entre os quais podemos citar: a questão do ser, a individualidade, o corpo, a alteridade, a angústia, a autenticidade, o desespero, etc. Ainda assim, novamente tal abordagem é passível de objeção, uma vez que esses são temas comuns em outros autores que não costumam ser identificados como existencialistas.

Embora não seja fácil resolver essa dificuldade, estou de acordo com alguns estudiosos do existencialismo ${ }^{10}$ que procuram acrescentar a tal delimitação de temas uma definição mais específica, visando com isso a circunscrever de modo mais adequado o escopo do existencialismo, ainda que, simultaneamente, a "intensão" permaneça suficientemente genérica para abarcar autores diversos que podem ser ligados em função de temáticas e posições semelhantes. Nesse sentido, além dos tópicos já apontados - ser, corpo, alteridade, autenticidade, etc -, o que caracterizaria essa corrente seria a defesa de que a análise da existência humana requer categorias novas, que não são encontradas no repertório

${ }^{9}$ LACEY, A. R. A Dictionary of Philosophy, p. 108.

10 Por exemplo, CROWELL Steven(ed.), The Cambridge Companion to Existentialism., 2012 e KAUFMANN, W., Existentialism from Dostoevsky to Sartre, 1968.

\begin{tabular}{|c|c|c|c|c|c|}
\hline intuitio & $\begin{array}{c}\text { ISSN } \\
1983-4012\end{array}$ & Porto Alegre & Vol.8 $-\mathrm{N}^{\circ} .2$ & $\begin{array}{c}\text { Dezembro } \\
2015\end{array}$ & p.04-14 \\
\hline
\end{tabular}


As origens existencialistas de Heidegger: a influência da teoria kierkegaardiana da comunicação indireta

conceitual do pensamento antigo e moderno. Entretanto, a negação por constatação de insuficiência ou de inadequação permanece, como toda negação, ligada dialeticamente ao objeto negado, e assim a justificação da instância específica do existencialismo se faria, num primeiro nível ou ponto de partida, em estrito diálogo com as soluções tradicionais.

Nessa base, a ideia é, por exemplo, que conceitos que pretendam apreender os "objetos em geral", como a noção de "substância", não seriam adequados para tratar daquilo que diz respeito à humanidade. $\mathrm{O}$ ser humano não poderia ser compreendido filosoficamente como um objeto entre outros. Para muitos existencialistas, portanto, a existência humana não seria nem substância com propriedades fixas, nem mero sujeito abstrato em um mundo de objeto. Para tratar filosoficamente da existência humana seria preciso, portanto, desenvolver uma nova rede de categorias, o que envolve, por consequência, uma alteração da própria tradição filosófica.

Dentro dessa linha, outras características comuns da corrente existencialista, também comuns a Kierkegaard e Heidegger, seriam: a tendência a ser anti-sistemática no tratamento dos problemas, tendência fundada numa suspeita de que o discurso puramente lógico, formal, doutrinal e "impessoal" frequentemente serve ao afastamento da verdade, afastamento muitas vezes formulado pelos existencialistas em termos de "abstrato" versus "concreto"; o posicionamento crítico em relação ao racionalismo em geral, afirmado ou simbolizado de modo mais ou menos explícito como uma espécie de categoria daquele antigo e inadequado filosofar "em universal" e "em abstrato"; adjacentemente, como corolário de tal orientação, evidencia-se uma pretensão de abordar o ser humano enquanto singularidade ou, sob outro aspecto, "em situação", deslocando assim o olhar - prima facie paradoxalmente - na direção de uma possível "teoria da particularidade" ou "da situacionalidade", valorizando filosoficamente experiências e dimensões que o filosofar anterior teria transcurado e mesmo silenciado, em geral ao subordinar ou não reconhecer uma originariedade ou centralidade ontológica a tais domínios, os quais a postura existencialista ao invés (ainda que sob variadas formas) reconhece e tematiza, em espaço próprio e em primeiro plano. Tal aspecto, aliás, sendo reconhecível não raramente também nas características por assim dizer "exteriores", de "tom" e "estilo", que caracterizam os pensadores dessa escola.

\section{Kierkegaard e a teoria da comunicação indireta}

Não é algo simples estabelecer todos os aspectos da teoria da comunicação indireta de Kierkegaard: encontramos considerações sobre essa questão em diversas obras e em contextos distintos. Além disso, alguns autores acreditam que haveria duas fases de sua formulação, onde a primeira

\begin{tabular}{|c|c|l|l|c|c|}
\hline intuitio & $\begin{array}{c}\text { ISSN } \\
1983-4012\end{array}$ & Porto Alegre & Vol.8 $-\mathrm{N}^{\circ} .2$ & $\begin{array}{c}\text { Dezembro } \\
2015\end{array}$ & p.04-14 \\
\hline
\end{tabular}


As origens existencialistas de Heidegger: a influência da teoria kierkegaardiana da comunicação indireta

apresentaria um viés mais irônico e provocador e a segunda uma intenção religiosa e ética ${ }^{11}$. Ainda assim, é possível apresentar de maneira unificada e coerente, ainda que em traços gerais, a concepção kierkegaardiana de comunicação indireta. Conforme já mencionei, além de ser uma clara fonte de inspiração para a filosofia heideggeriana e a formulação do método das indicações formais, sua exposição permite também analisar certos aspectos do pensamento de Kierkegaard que costumam ser negligenciados, além de ajudar a situá-lo como um existencialista ${ }^{12}$.

Kierkegaard contrasta a comunicação indireta com a comunicação direta. A segunda diz respeito à comunicação objetiva e com pretensão de validade universal, típica dos discursos científicos, lógicos e de caráter impessoal. A comunicação indireta, no entanto, possui um caráter subjetivo e "secreto", correspondendo aos diálogos pessoais, aos textos literários e poéticos e à fala místico-religiosa. Seu conteúdo, ao contrário do conteúdo de um tratado científico, costuma não ser objetivo e exato, pois depende essencialmente da apreensão subjetiva do interlocutor. Muitas vezes o conteúdo da comunicação indireta é propositalmente ambíguo, podendo ser interpretado de diferentes formas (ainda que haja uma unidade temática e semântica). Por depender da interpretação do interlocutor, a comunicação indireta aponta para a necessidade da realização da comunicação através da apreensão concreta do conteúdo apreensão essa que pode dar-se de muitos modos, uma vez que o significado do conteúdo não é de todo fixo e unívoco ${ }^{13}$.

Assim, a ideia de comunicação indireta aponta claramente para aspectos existencialistas na filosofia kierkegaardiana: na análise da linguagem e do discurso comunicativo não basta uma compreensão abstrata de sua realização, mas também surge a necessidade de indicar o fato de que há múltiplos usos da linguagem, incluindo aqueles que exigem uma apropriação hermenêutica por parte do interlocutor e que, por isso, apontam para sua multiplicidade de desdobramentos. Entender, portanto, que somente a comunicação direta - científica, exata, impessoal e fixa - possa ser considerada digna de menção e análise seria fruto de um preconceito típico da tradição filosófica racionalista, a qual, segundo o filósofo, precisa ser questionada e confrontada.

Nas palavras de Kierkegaard:

11 Ver POOLE, Roger. Kierkegaard: The Indirect Communication, 1993, p. 23-5.

12 É notório também que a maioria dos comentadores de Heidegger não desenvolve a relação entre a teoria da comunicação indireta e as indicações formais, geralmente limitando-se a apontar sua existência. As exceções parecem ser Pöggeler (PÖGGELER, Otto. Destruction and Moment, 1994) e Van Buren (VAN BUREN, John. The Young Heidegger: Rumor of the Hidden King,1994), conforme indico a seguir.

13 Segundo Van Buren (VAN BUREN, John. The Young Heidegger: Rumor of the Hidden King, 1994, p. 327-8): "O apontamento da comunicação indireta é supor conduzir os leitores à verdade subjetiva que pode ser encontrada em suas próprias situações históricas. Há aqui tanto um momento negativo de repelir e apontar para outra direção, quanto um momento positivo de dirigir e apontar para algo. (...) O momento afastante na comunicação consiste em repelir a confiança no mens auctoris do escritor e do conteúdo direto da comunicação. (...) De acordo com Kierkegaard, o momento positivo da comunicação indireta consiste no fato de que seus 'fragmentos filosóficos', seus 'fragmentos e partes de pensamento sistemático', são 'sinais' apontando na direção de uma 'apropriação pessoal' e concreta".

\begin{tabular}{|c|c|c|c|c|c|}
\hline intuitio & $\begin{array}{c}\text { ISSN } \\
1983-4012\end{array}$ & Porto Alegre & Vol.8 $-\mathrm{N}^{\circ} .2$ & $\begin{array}{c}\text { Dezembro } \\
2015\end{array}$ & p.04-14 \\
\hline
\end{tabular}


As origens existencialistas de Heidegger: a influência da teoria kierkegaardiana da comunicação indireta

Não é verdade que a comunicação direta é superior à comunicação indireta. Não, não. Mas o fato é que jamais nasceu algum ser humano que pudesse usar o método indireto sequer razoavelmente bem, e ainda menos usá-lo em toda sua vida. Nós seres humanos precisamos uns dos outros, e nisso já reside uma direção. (...) Quando uma pessoa usa o método indireto, há, de um modo ou outro, algo endiabrado nisso, mas não necessariamente no sentido ruim - como, por exemplo, com Sócrates. A comunicação direta, de fato, torna a vida mais fácil. Por outro lado, o uso da comunicação direta pode ser humilhante para uma pessoa que usou a comunicação indireta talvez egoisticamente (nesse caso, no sentido ruim de endiabrado). (...) Para mim a comunicação indireta têm sido instintiva, pois ao me tornar um autor eu sem dúvida me desenvolvi e, consequentemente, todo esse movimento está obtuso (e isso é a razão pela qual, desde o princípio, não pude estabelecer meu plano diretamente, embora certamente eu estivesse ciente de que muito estava fermentando em mim). (...) Eu poderia muito bem ter dito logo: sou um autor religioso ${ }^{14}$.

Assim, ao comparar os dois tipos de comunicação, Kierkegaard toma partido pela comunicação indireta - inclusive filiando-se explicitamente a ela enquanto autor - mas, ainda assim, reconhece que seu uso na vida cotidiana é tarefa complicada. É comum o filósofo referir-se à comunicação indireta como um tipo de "arte", da qual poucos conseguiriam fazer um uso adequado. A figura de Jesus Cristo é diversas vezes associada ao exemplo máximo da perfeita comunicação indireta: não somente por sua mensagem através de parábolas, mas também por ser ele quem falava - não se trata somente do que é dito, mas do modo como é dito e por quem é dito. As mesmas palavras de Cristo proferidas por alguém que não as realizasse em atitudes e comportamentos, pareceria a Kierkegaard uma deturpação de sua mensagem.

Esse é outro aspecto propriamente existencialista da tal teoria: uma característica essencial da comunicação indireta é que ela envolve uma apropriação por parte daquele que se envolve com ela, de modo que se liga diretamente com aspectos da própria vida de quem a utiliza. Quando, por exemplo, nos deparamos com um discurso político ou religioso, não prestamos atenção apenas nas palavras proferidas no conteúdo do discurso - mas também na sua forma, no modo como se fala, assim como em todo o contexto que cerca aquele momento. Da mesma maneira, discursos dessa natureza não são avaliados apenas do ponto de vista lógico, mas envolvem também uma consideração de caráter ético: a preleção de um político corrupto ou de um sacerdote hipócrita não tem o mesmo impacto de convencimento e comoção do que aqueles vindos de pessoas tidas como honestas.

Além disso, Kierkegaard mostra que, paradoxalmente, a verdadeira comunicação indireta possui um aspecto endiabrado, ainda que não necessariamente em sentido negativo: aquele que assim se comunica quer provocar uma transformação em seus interlocutores. A intenção é ir além do óbvio e desafiar os ouvintes ou leitores. Por isso, muitas vezes, a comunicação indireta pode parecer irreverente ou furiosa, e o uso de ironias e sarcasmo pode estar presente. Um exemplo disso são os diálogos entre Sócrates e os atenienses: a maiêutica socrática era um método de comunicação indireta por excelência - e

${ }^{14}$ KIERKEGAARD, Søren. The point of view, 1998, p. 248-9.

\begin{tabular}{|c|c|l|l|c|c|}
\hline intuitio & $\begin{array}{c}\text { ISSN } \\
1983-4012\end{array}$ & Porto Alegre & Vol.8 $-\mathrm{N}^{\mathrm{o} .2}$ & $\begin{array}{c}\text { Dezembro } \\
2015\end{array}$ & p.04-14 \\
\hline
\end{tabular}


As origens existencialistas de Heidegger: a influência da teoria kierkegaardiana da comunicação indireta

o fato de que fosse considerada por muitos como incômoda é, antes, uma comprovação disso ${ }^{15}$. Mas é claro que pode também haver um uso indevido desse tipo de comunicação e uma retórica malintencionada pode se tornar ainda mais nociva quando emprega o método indireto.

Essas questões demonstram que o filósofo dinamarquês estava de fato interessado em uma análise da linguagem e do discurso como ele de fato acontece na nossa experiência concreta: o exemplo de Sócrates é ilustrativo justamente por toda a sutileza da sua fala, carregada de metáforas, histórias e ironia. Nesse sentido, as considerações kierkegaardianas configuram o que poderíamos chamar propriamente de uma filosofia da linguagem existencialista, em contraste com análises filosóficas da linguagem que tratam desse fenômeno apenas do ponto de vista da lógica.

Porém, justamente levando em conta a comunicação cotidiana, Kierkegaard reconhece a necessidade da comunicação direta: na maior parte das vezes precisamos ser objetivos em nossas expressões e não dar lugar a ambiguidades. O próprio funcionamento de uma sociedade depende da simplificação e objetividade da comunicação, o que não deve significar, no entanto, confinar a comunicação a essa esfera. Que a comunicação indireta seja, nesse sentido, menos útil e prática não implica que deva ser considerada inferior à comunicação direta, mas apenas que sua utilização envolve um campo mais complexo e sofisticado, o que justifica também a dificuldade de empregá-la.

Como diz Kierkegaard, "toda comunicação de conhecimento é uma comunicação direta. E toda comunicação de capacidades é, mais ou menos, uma comunicação indireta" ${ }^{\text {"16 }}$. Essa outra diferença entre os dois tipos de métodos comunicativos revela suas intenções: a comunicação direta, por tratar de questões objetivas, procura transmitir conhecimentos e, portanto, é fundamental que exista clareza na sua utilização. A comunicação indireta, por sua vez, quer transformar o comportamento do interlocutor, o que faz com que foque não tanto em teorias, mas sim nas capacidades que o outro pode adquirir. É o que deveria ocorrer, segundo Kierkegaard, quando ensinamos alguém sobre o modo correto de agir: mais do que pregar uma teoria sistemática sobre preceitos éticos, vale o exemplo concreto de uma ação ética - a qual é mais efetiva ao ser demonstrada do que ao ser explicada -, e assim é possível suscitar no outro sua própria capacidade de agir corretamente. Como diz o filósofo: “o que eu tenho chamado de genuína comunicação-arte, isso é indireto ou pelo menos essencialmente indireto. A comunicação ética, por sua vez, é incondicionalmente indireta" ${ }^{\prime 17}$.

15 Como explica Poole (POOLE, Roger. Kierkegaard: The Indirect Communication, 1993, p. 9-10): "O objetivo da primeira comunicação indireta é envolver o leitor (...). O leitor deve ser apanhado como um potencial aliado, seduzido e intrigado pelas emboscadas retóricas do texto e então envolvido em uma espécie de trabalho de detetive, até o ponto em que - em condições ideais - não haja nenhuma simples instrução, ou doutrina, ou fato objetivo para ser tomado, mas apenas a experiência de perplexidade mutuamente compartilhada".

${ }^{16}$ KIERKEGAARD, Søren. Søren Kierkegaard's Journals and Papers, 1967, p. $248-9$.

${ }^{17}$ KIERKEGAARD, Søren. Søren Kierkegaard's Journals and Papers, 1967, p. 248-9.

\begin{tabular}{|c|c|l|l|c|c|}
\hline intuitio & $\begin{array}{c}\text { ISSN } \\
1983-4012\end{array}$ & Porto Alegre & Vol.8 $-\mathrm{N}^{\circ} .2$ & $\begin{array}{c}\text { Dezembro } \\
2015\end{array}$ & p.04-14 \\
\hline
\end{tabular}


Juliana Missaggia

As origens existencialistas de Heidegger: a influência da teoria kierkegaardiana da comunicação indireta

\section{A influência da teoria da comunicação indireta no pensamento heideggeriano}

Dadas tais considerações, podemos perceber como a teoria da comunicação indireta influenciou o pensamento heideggeriano, sobretudo no que diz respeito a aspectos metodológicos de sua obra, como o método das indicações formais, empregadas largamente em Ser e Tempo, assim como, em geral, a aspectos propriamente "existencialistas" na filosofia de Heidegger. Em primeiro lugar, é bastante claro como a comunicação indireta atribui grande importância à realização concreta do que foi comunicado através da interpretação e atitude do interlocutor. O método indireto, assim como as indicações formais, não pode ser efetivado sem que se leve em consideração a apropriação do outro em relação ao que foi falado ou escrito. Esse é um aspecto bastante semelhante ao momento de realização (Vollzug) das indicações formais, que aponta para o momento, o modo e as condições nas quais ocorre a apreensão do fenômeno ${ }^{18}$. Também na teoria da comunicação indireta são fundamentais esses fatores, pois sem eles a comunicação seria algo indiferente à situação daquele que recebe a informação e que deve interpretá-la.

Do mesmo modo que no caso do pensamento kierkegaardiano, aqui também fica claro os aspectos existencialistas desse modo de proceder: o filósofo alemão não aceita a ideia de que a linguagem e a comunicação em geral possa ser analisada apenas abstratamente, como no caso da investigação restrita ao seu conteúdo proposicional. Sempre que algo é dito, há o contexto e o modo como isso é comunicado, e tais aspectos devem ser fatores levados em consideração. Essas questões remetem inclusive para desdobramentos éticos já mencionados, já que a comunicação envolve tanto um direcionamento em relação ao outro, como também um modo de se "colocar", de se afirmar em um "eu sou" que ultrapassa o conteúdo formal do discurso ${ }^{19}$.

Além disso, podemos observar também outra semelhança importante, que releva claramente a influência de Kierkegaard sobre Heidegger: o modo como o conteúdo é concebido na comunicação indireta é essencialmente aberto. Uma vez que faz parte de sua formulação apresentar certa ambiguidade e equivocidade, a fixação do conteúdo em cada ato comunicativo vai depender de outros fatores. O mesmo ocorre com as indicações formais, pois elas não pretendem descrever um estado de coisas estático, mas

\footnotetext{
${ }^{18}$ Como apontado anteriormente, não apresento aqui uma explicação detalhada das características das indicações formais, de modo que se o objetivo é se situar em relação ao tema, indico o trabalho de Streeter (STREETER, Ryan. Heidegger's Formal Indication: a Question of Method in Being and Time.).

19 Segundo Pöggeler (PÖGGELER, Otto. Destruction and Moment. 1994, p. 142): "O próprio Heidegger procurou desenvolver o chamar-a-atenção realizado pela comunicação indireta como uma hermenêutica indicativo-formal. (...) Se o ser humano é definido como existência, então essa existência não deve ser tomada em uma 'reflexão teórica', mas somente em sua realização [Vollzug] no 'eu sou'. Um ser humano não é um mero caso particular da realização de um universal. No trabalho teórico, assim como no trato cotidiano, tomamos as coisas como casos indiferentes de instanciação universal. (...) O ser humano não pode compreender a si mesmo desse modo porque, devido a sua facticidade, ele abre a si mesmo para o universal somente historicamente e em um tempo particular. Se a comunicação indireta é desdobrada como uma indicação formal, então está negada a possibilidade de seguir as concepções de existência de Kierkegaard ou mesmo de Nietzsche de modo acrítico".
}

\begin{tabular}{|c|c|c|c|c|c|}
\hline intuitio & $\begin{array}{c}\text { ISSN } \\
1983-4012\end{array}$ & Porto Alegre & Vol.8 $-\mathrm{N}^{\circ} .2$ & $\begin{array}{c}\text { Dezembro } \\
2015\end{array}$ & p.04-14 \\
\hline
\end{tabular}


As origens existencialistas de Heidegger: a influência da teoria kierkegaardiana da comunicação indireta

sim apontar uma direção geral para a realização concreta do conteúdo. Ao tomar o conteúdo como apenas um elemento - e não o elemento central e determinante -, tanto a comunicação indireta como as indicações formais revelam um aspecto não objetificante da comunicabilidade.

Fica evidente, assim, o que já foi apontado anteriormente, acerca de um aspecto em certo sentido "realista" dessa análise de caráter existencialista: a compreensão da comunicação quando vai além da sua dimensão meramente direta permite descrever uma série de fenômenos de um modo mais amplo. Com ela podemos indicar a necessidade de observar o contexto e as motivações por trás do discurso, as quais nem sempre são explícitas, pois é notório que o mesmo conjunto de proposições pode possuir um significado bastante diferente dependendo do contexto em que é proferido e do modo como é proferido. Uma frase bastante simples como "amanhã haverá uma tempestade", pode ser entendida como um acontecimento grave ou absolutamente banal, de acordo com o contexto que envolve a proposição. Do mesmo modo, a ironia, o eufemismo, o sarcasmo e outras figuras de linguagem só são compreensíveis porque o discurso não se resume a proposições rígidas tomadas isoladamente.

Outra questão digna de nota é que a comunicação indireta aponta para um novo elemento fundamental do método das indicações formais, intimamente ligado com aspectos existencialistas da filosofia heideggeriana: do mesmo modo que o comunicar de caráter indireto pretende suscitar uma ação e transformação no interlocutor, também as indicações formais aspiram estabelecer um tipo de atividade filosófica que envolva o Dasein em sua existência concreta. Uma vez que em ambos os procedimentos é necessário a realização através do outro - do interlocutor, no caso da comunicação indireta, e do filósofo, no caso da indicação formal -, há um fator de transformação que envolve aquele que concretiza a atividade, pois o que está em questão é sua própria concepção de realidade e sua própria capacidade de agir, seja ao comunicar, seja ao filosofar. Já que não se trata de uma apreensão objetiva e previamente determinada, não é possível saber quais serão os resultados e consequências da atividade até que ela seja efetivamente realizada.

Desse modo, mais do que uma influência secundária, como por vezes é compreendida, a obra de Kierkegaard foi uma das bases fundamentais no período de formação de Heidegger, de modo que mesmo que nem sempre seja citado explicitamente pelo filósofo alemão, seu pensamento pode ser considerado um dos fundamentos por trás do projeto filosófico que resultou em Ser e Tempo. Conforme mencionado, embora o escopo desse estudo se limite a um ponto particular do vínculo entre os filósofos, a análise da relação entre as obras de Kierkegaard e Heidegger é interessante não somente devido à inspiração que o primeiro exerceu no segundo para a formulação de conceitos particulares - como a indicação formal e a concepção de linguagem -, mas também na medida em que fornece elementos para compreender e interpretar a obra heideggeriana a partir de um viés existencialista, questionando suas origens para além da vinculação com a fenomenologia.

\begin{tabular}{|c|c|l|l|c|c|}
\hline intuitio & $\begin{array}{c}\text { ISSN } \\
1983-4012\end{array}$ & Porto Alegre & Vol.8 $-\mathrm{N}^{\circ} .2$ & $\begin{array}{c}\text { Dezembro } \\
2015\end{array}$ & p.04-14 \\
\hline
\end{tabular}


As origens existencialistas de Heidegger: a influência da teoria kierkegaardiana da comunicação indireta

\section{Referências}

CROWELL Steven (ed.), The Cambridge Companion to Existentialism. Cambridge University Press, 2012. FRIEDMAN, R. Z. Kierkegaard: First Existentialist or Last Kantian?. Religious Studies, v. 18, n. 02, p. 159-170, 1982. http://dx.doi.org/10.1017/S0034412500013755

GADAMER, Hans-Georg. Los caminos de Heidegger. Trad. Ángela Ackermann Pilári. Barcelona: Herder, 2002.

HEIDEGGER, Martin. (GA 17). Einführung in die phänomenologische Forschung (Wintersemester 1923/24). Frankfurt am Main: Vittorio Klostermann, 1994.

HEIDEGGER, Martin. (GA 60). Phänomenologie des Religiösen Lebens (Wintersemester 1920/21). Frankfurt am Main: Vittorio Klostermann, 1995a.

HEIDEGGER, Martin. (GA 63). Ontologie (Hermeneutik der Faktizität) (Sommersemester 1923). Frankfurt am Main: Vittorio Klostermann, 1995b.

HEIDEGGER, Martin (1927). Sein und Zeit. Achtzehnte Auflage. Unveränderter Nachdruck der fünfzehnten, an Hand der Gesamtausgabe duchgesehenen Auflage. Tübingen: Max Niemeyer Verlag, 2001a.

INWOOD, Michael. Dicionário Heidegger. Rio de Janeiro: Jorge Zahar Editor, 2002.

KAUFMANN, W., Existentialism from Dostoevsky to Sartre. Cleveland: Meridian Books, 1968.

KENNY, A. A New History of Western Philosophy, Oxford: Oxford University Press, 2010.

KIERKEGAARD, Søren, The Concept of irony, with Constant Reference to Socrates, trans. Lee M. Capel. London: Collins Press, 1966.

KIERKEGAARD, Søren. The point of view; edited and translated with introduction and notes by Howard V. Hong and Edna H. Hong. Princeton, N.J.: Princeton University Press, 1998.

KIERKEGAARD, Søren. Søren Kierkegaard's Journals and Papers: Volume 1, A-E. Bloomington: Indiana University Press, 1967.

KISIEL, Theodore. The Genesis of Heidegger's Being and Time. Bekeley, Los Angeles, London: University of California Press, 1993.

POOLE, Roger. Kierkegaard: The Indirect Communication. Charlottesville and London: University Press of Virginia, 1993.

PÖGGELER, Otto. Destruction and Moment. In: KISIEL, T. \& VAN BUREN, J. (orgs). Reading Heidegger from the Start. Albany: State University Press of New York, 1994, p. 137-158.

STREETER, Ryan. Heidegger's Formal Indication: a Question of Method in Being and Time. Man and World, vol. 30 (1977), pp. 413-430.

VAN BUREN, John. The Young Heidegger: Rumor of the Hidden King. Indianapolis, Indiana: Indiana University Press, 1994.

LACEY, A. R. A Dictionary of Philosophy. 3rd Edition; Routledge, London, 1996.

Recebido em: 30/11/2015

Aprovado para a publicação em: 02/12/2015

\begin{tabular}{|c|c|l|l|c|c|}
\hline intuitio & $\begin{array}{c}\text { ISSN } \\
1983-4012\end{array}$ & Porto Alegre & Vol.8 $-\mathrm{N}^{\mathrm{o}} .2$ & $\begin{array}{c}\text { Dezembro } \\
2015\end{array}$ & p.04-14 \\
\hline
\end{tabular}

